\title{
Editorial - El legado de un visionario
}

Les presento con mucho placer la edición número 17 de la revista Memoria Investigaciones en Ingeniería, que se ha venido publicando de manera sostenida desde el año 2000. En estos años transcurridos ha habido un crecimiento sistemático en cuanto a la participación internacional y al establecimiento de redes de colaboración con autores e instituciones de diversos países, así como un proceso de profesionalización de la gestión de la revista y un proceso de mejora para lograr alcanzar mejores estándares internacionales.

Todo lo anterior, no hubiera sido posible sin el esfuerzo y visión de quien fue el editor durante los primeros 17 años de la revista, es decir casi toda su historia: el Ing. Manuel Vega. Manuel, para quienes no lo conocen, es un ingeniero, español, dedicado al área de metalurgia, con larga proyección en la industria, que se unió a la Facultad de Ingeniería de la Universidad de Montevideo (FIUM) como vice-decano para liderar la FIUM. A pesar de no tener una trayectoria como científico ni estudios de posgrado, tuvo la visión hace ya varios años, de que la FIUM debería apostar a la investigación. Promovió para ello la formación de doctores en centros de investigación internacionales (como fue mi caso), y creó una revista que permitió inicialmente publicar los primeros resultados de investigación. Su trabajo durante estos años fue callado, detallista y, sobretodo, realizado con mucho empeño para enfrentar los desafíos que se presentan al publicar una revista científica. Hoy, que estoy a cargo de su edición, valoro mucho más aún, el trabajo oculto realizado durante todos estos años para publicar cada edición de la Revista, como si fuera algo sencillo. Todavía tenemos mucho que aprender, y ahora que se ha jubilado y está dedicado a otras cosas importantes que tiene la vida, lo extrañamos por su labor y por el cariño que le dedicó a la Revista. ¡Gracias Manuel por tu legado!

Todo lo anterior se enmarca en la celebración de los 25 años de la FIUM, con el lema de "25 años formando ingenieros". En palabras del actual decano de la Facultad, el Dr. Claudio Ruibal, quien ha estado además desde el inicio de la Universidad, "Estos primeros veinticinco años los vemos -ahora, en retrospectiva- como una gran obra de teatro, en la que los personajes entran y salen del escenario, mientras los actos se suceden con el rítmico pasar de los semestres. Se me antoja una obra de teatro y no una película, porque en FIUM no hay efectos especiales, no hay montajes, no hay edición posterior, no hay chance de repetir un acto. Todo sucede en tiempo real, siguiendo el guion y, a la vez, con cierto grado de improvisación, nacida de una gran confianza en el equipo y en cada uno de sus miembros. ¿Quiénes son los actores de esta obra? Somos los profesores, los alumnos, los graduados, el personal no docente, los servicios centrales de apoyo, los proveedores, las empresas con, y para, las que hacemos proyectos de investigación y las que contratan a nuestros graduados, los alumnos de intercambio y los profesores internacionales invitados. ¿Y los espectadores? Nuestras familias y la sociedad en su conjunto: las familias de los profesores, de los alumnos, de los graduados, del personal no docente, etc. ¡Cuántas anécdotas se cuentan cada día, en nuestros hogares, de lo que sucede en la FIUM!"

Luego de esta larga introducción, me gustaría presentar los siete trabajos científicos que componen esta edición número de 17 de la Revista. Estos artículos fueron escritos por un total de 20 autores, en centros de investigación ubicados enAlemania, Brasil, México, Perú y Uruguay. El 80\% de los autores tienen filiación foránea con relación a la Revista, lo cual muestra el avance de su proceso de internacionalización. Esta edición incluya una extensa diversidad de temas con trabajos sobre: la aplicación de redes neuronales en smartgrids, soluciones para la distribución urbana de carga, análisis sobre revenue management en aerolíneas comerciales, estudio sobre el comportamiento causa efecto no-lineal en la gestión de proyectos, comparativa de diseños de sistemas de locutor, análisis de las competencias necesarias para la transformación agroindustrial 4.0, y la aplicación de un modelo de reducción de costos asociados al consumo de agua en una industria de refrescos. Gracias a los autores y espero que los lectores disfruten del contenido de los mismos, que han sido revisador por 20 revisores externos.

Por último, quisiera agradecer y destacar que esta edición es fruto del esfuerzo y dedicación de Andrea Russi Phd (c), quien apoyó todas las etapas de esta transición y del apoyo de la Lic. Valentina Morandi quien brindó los servicios de biblioteca de la Universidad de Montevideo. Con este apoyo ambas, se ha hecho posible que este año migremos hacia un sistema de Open Journal (OJS), lo que implica un cambio en el sitio web, una nueva manera de gestionar y almacenar la Revista.

Gracias por ayudarnos a atrevernos a tanto cuanto podemos,

\author{
Martin Tanco, PhD. \\ Director Editor \\ Facultad de Ingeniería \\ Universidad de Montevideo
}

